\title{
Dynamic modeling and simulation of a multi-effect distillation plant
}

\author{
Lidia Roca $^{1} \quad$ Luis J. Yebra ${ }^{1} \quad$ Manuel Berenguel $^{2} \quad$ Alberto de la Calle $^{1}$ \\ ${ }^{1}$ CIEMAT-PSA, Ctra. Senés s/n, 04200 Tabernas, Almería, Spain \\ Centro de Investigaciones Energéticas, MedioAmbientales y Tecnológicas \\ Plataforma Solar de Almería \\ ${ }^{2}$ Dep. Lenguajes y Computación, Universidad de Almería, \\ Ctra. Sacramento s/n, 04120 Almería, Spain \\ \{lidia.roca,luis.yebra,alberto.calle\}@psa.es,beren@ual.es
}

\begin{abstract}
This paper describes a model which simulates the dynamics of a multi-effect distillation system in different operating conditions. It has been designed to improve the operation of the process and develop a control strategy which optimizes the distillate production. The physical models are based on conservation equations of mass and energy. They also include experimental correlations for heat transfer coefficients. Conservation laws are applied in different components, such as the heater, the effects and the preheaters. The results of the mathematical model simulation of the whole process show promising outcomes.
\end{abstract}

Keywords: solar desalination, multi-effect distillation, modeling

\section{Introduction}

One of the challenges today is the production of freshwater for those population areas with high water stress. For places close to the sea, the desalination process provides an excellent way to tackle this problem. The use of desalination plants in these regions with plentiful seawater resources is becoming a technological way to produce freshwater. Since large-scale desalination typically requires large amounts of energy, a solution is coupling desalination plants with renewable energies [10]. This process can be performed in various ways, for instance, using solar energy in which the source that provides the heat for the desalination process is collected in a solar field.

Multi-effect distillation plants (MED) raise a great interest in industry due to its efficiency when they are coupled with a solar thermal system. This kind of sys- tems is gaining more acceptance as a result of their lower energy requirements, higher heat transfer coefficients, compactness, high product water quality and low pre-treatment $[2,7]$. In the literature there is a wide variety of steady-sate models for MED plants $[3,5,6,9]$. One of the last works is the one developed in [13], which shows a hybrid system that combines a desalination system with solar and wind energies. In that paper, the model includes the distillation unit, the flat-plat collectors and the wind system. Regarding dynamic models, the literature about multi-effect distillation systems is scarce $[4,8]$.

The innovation of the present paper is that the dynamic model has been developed with the object-oriented Modelica language using the Dymola tool and the Modelica.Thermal library. This framework has allowed us to develop new libraries to make simulations easier and improve the operating procedure.

\section{Description of the system}

The AQUASOL system (Figure 1) at CIEMATPlataforma Solar de Almería (PSA), located in the South of Spain, proposes a solar distillation technology that consists of a compound parabolic collector (CPC) solar field, two $12 \mathrm{~m}^{3}$ water storage tanks, a multi-effect distillation unit with a $3 \mathrm{~m}^{3} / \mathrm{h}$ nominal distillate production, and a double effect $\left(\mathrm{LiBr}-\mathrm{H}_{2} \mathrm{O}\right)$ absorption heat pump (DEAHP) [1].

The desalination plant at CIEMAT-PSA is a forward-feed multi-effect distillation unit manufactured and delivered by Weir ENTROPIE (Paris, France) in 1987. It has 14 cells, or effects, in a vertical arrangement. The original first cell that worked with low-pressure saturated steam $\left(70{ }^{\circ} \mathrm{C}, 0.31\right.$ bar [11]) 


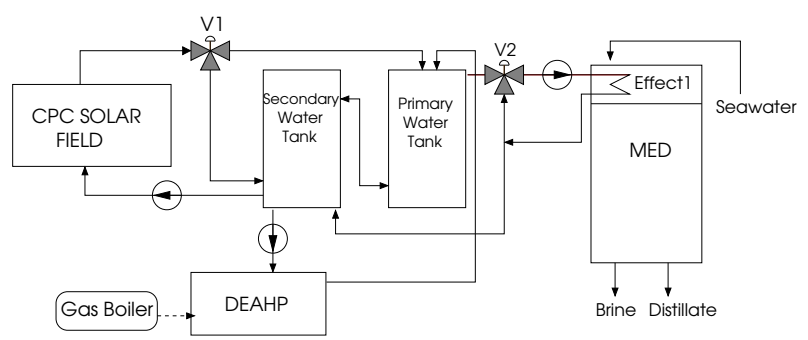

Figure 1: AQUASOL diagram

was replaced in the AQUASOL project by a new one, which works with hot water coming directly from a thermal storage tank. For optimal operation, the inlet feed-water temperature in the first cell must be around $66.5^{\circ} \mathrm{C}$. It is possible to reach this temperature with heat from a solar field as well as with steam generated by an auxiliary gas boiler coupled to a double effect absorption heat pump that can work at variable steam loads (from $30 \%$ to $100 \%$ ).

Seawater is preheated on its way toward the first cell of the plant, which is at the top of the desalination tower. Vapour is produced in this first effect (or heater) using the hot water from the storage system. This vapour flows to the preheater- 1 and part of the latent heat is transferred to the seawater that flows inside this preheater, increasing the temperature of the seawater. The steam produced in the first effect goes to the effect-2, where it is condensed in a tube bundle sprayed with the more concentrated brine which falls by gravity from the previous effect. The latent heat released by condensation of the vapour allows part of the seawater entering the second effect to evaporate at a lower temperature/pressure. This condensation/evaporation process is repeated in the successive effects. Finally, the vapour produced in the effect-14 is condensed in a final condenser cooled by seawater.

\section{The dynamic model}

The model of the MED unit is based on the following assumptions:

- no heat losses with the atmosphere,

- no flash vapour is produced,

- the final distillate production is the sum of the distillate produced in each effect,

- the temperature drop in each effect is equal to the temperature difference in the preheaters,
- the preheater-14 is considered as the final condenser.

Each component of the plant (the heater, the effects and the preheaters) has been modeled in the Modelica language using Modelica.Thermal library. Figure 2 shows the final model of the MED unit, which includes the heater, 13 effects and 14 preheaters.

The inputs of the model are the feedwater mass flow rate to the heater, $\dot{m}_{M}$, the inlet temperature to the heater, $T_{i M}$, the salt concentration of the seawater coming into the heater, $C_{B 0}$, the pressure in each effect, the seawater mass flow rate, $\dot{m}_{s w}$, and the inlet seawater temperature to the preheaters 14 and 13 . The outputs of the model are the outlet temperature from the heater, $T_{O M}$, and the distillate production, $\dot{m}_{d}$. The correlations of the heat transfer coefficients included in the models were obtained from experiments carried out in the real plant [12]. Nomenclature and subscripts are shown in Tables 1, 2.

Table 1: Nomenclature

\begin{tabular}{|c|l|c|}
\hline Name & Description & Units \\
\hline$A$ & Surface area & $\mathrm{m}^{2}$ \\
$B P E$ & Boiling Point Elevation & $K$ \\
$C$ & Concentration & $\%$ \\
$C_{p}$ & Specific heat capacity & $\mathrm{J} / \mathrm{kgK}$ \\
$d T$ & Temperature difference & \\
& between successive effects & $K$ \\
$h$ & Specific entalphy & $\mathrm{J} / \mathrm{kg}$ \\
$\dot{m}$ & Mass flow rate & $\mathrm{kg} / \mathrm{s}$ \\
$M$ & Mass & $\mathrm{kg}$ \\
$P$ & Pressure & $\mathrm{Pa}$ \\
$Q$ & Heat transfer rate & $\mathrm{W}$ \\
$T$ & Temperature & $K$ \\
$U$ & Overall heat trasfer coefficient & $\mathrm{W} / \mathrm{m}^{2} \mathrm{~K}$ \\
$\lambda$ & Latent heat of vaporization & $\mathrm{J} / \mathrm{kg}$ \\
\hline
\end{tabular}

Table 2: Subscripts

\begin{tabular}{|c|l|}
\hline Name & Description \\
\hline$B$ & Brine \\
$d$ & Distillate \\
$e$ & Effect \\
$h$ & Heater \\
$i$ & Inlet \\
$k$ & Effect identification number \\
$M$ & MED heating water \\
$o$ & Outlet \\
$p$ & Preheater \\
\hline
\end{tabular}




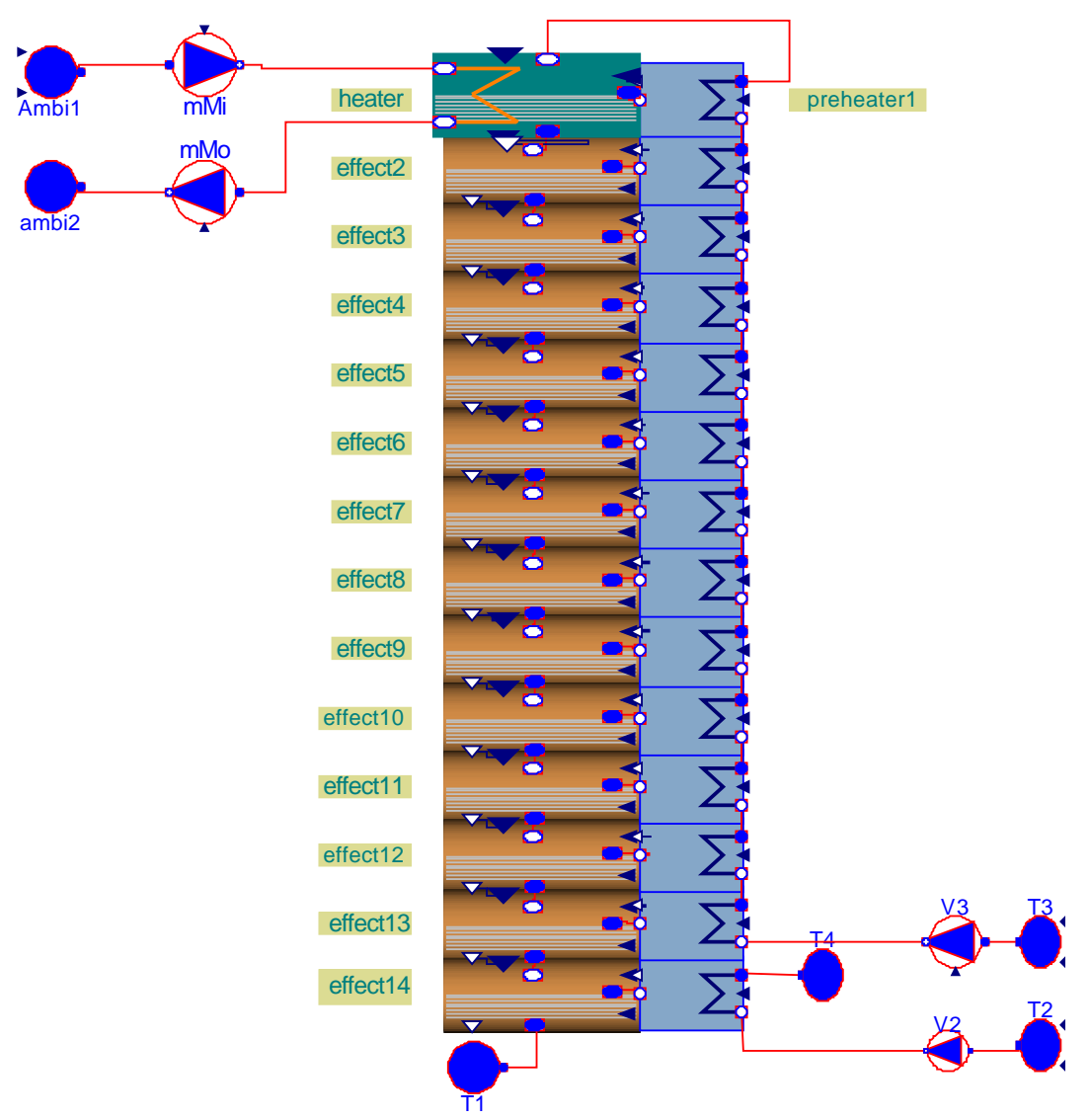

Figure 2: Modelica model of the MED unit

\begin{tabular}{|c|l|}
$s w$ & Seawater \\
$v$ & Saturated vapour \\
\hline
\end{tabular}

\subsection{The heater}

The first effect of the MED plant is the heater. Hot water coming from a storage system enters the heat exchanger and produces the first evaporation of the seawater. Fig. 3 shows the model of the heater.

The heat transfer rate for the first effect can be calculated from the MED heating water mass flow rate, $\dot{m}_{M}$, and the MED heating water temperature difference in stationary conditions as follows:

$$
Q_{h}=\dot{m}_{M} \cdot C_{p} \cdot\left(T_{i M}-T_{o M}\right)
$$

Using the log-mean temperature and the overall heat transfer coefficient, $U_{h}$, the heat transfer rate can be written as:

$$
Q_{h}=U_{h} \cdot A_{h} \cdot \frac{\left(T_{i M}-T_{v 1}\right)-\left(T_{O M}-T_{v 1}\right)}{\ln \frac{T_{i M}-T_{v 1}}{T_{o M}-T_{v 1}}}
$$

where $T_{v 1}$ is the saturation temperature of the vapour generated in the heater.
Distillate mass flow produced in the heater can be estimated using the latent heat of vaporization, $\lambda$ :

$$
\dot{m}_{d h}=\frac{Q_{h}}{\lambda}
$$

Since the vapour pressure of the aqueous solution is lower than that of pure water at the same temperature, the boiling point of the solution will be higher than that of the water. Therefore, the temperature of the brine can be obtained using the boiling point elevation, BPE:

$$
T_{B 1}=T_{v 1}+B P E
$$

The BPE is a brine property and depends on the brine salinity and temperature.

The mass flow rate and concentration of the brine can be obtained applying mass and energy balances.

Mass balance:

$$
\frac{d}{d t}\left(M_{B 1}\right)=\dot{m}_{s w}-\dot{m}_{B 1}-\dot{m}_{d 1}
$$

Salt mass balance:

$$
\frac{d}{d t}\left(M_{B 1} \cdot C_{B 1}\right)=\dot{m}_{s w} \cdot C_{B 0}-\dot{m}_{B 1} \cdot C_{B 1}
$$




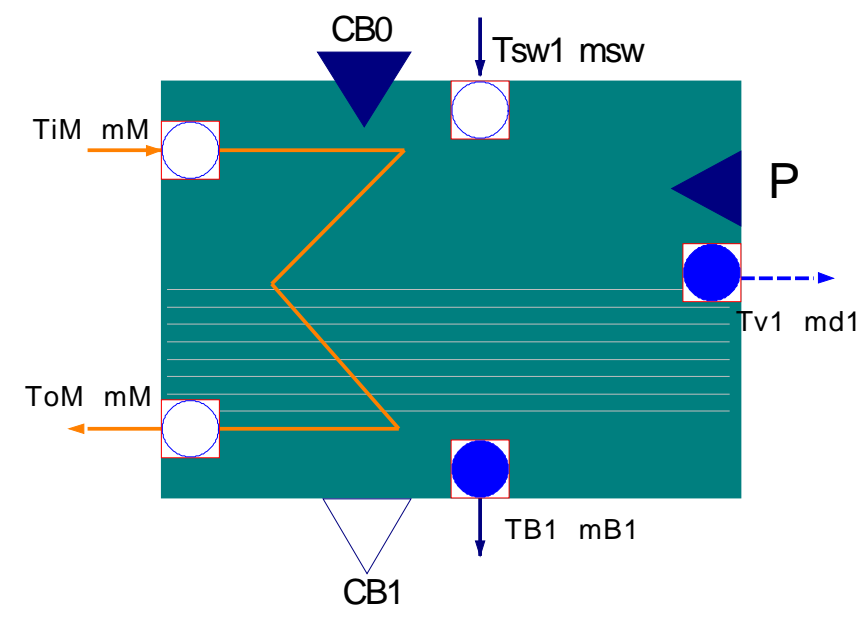

Figure 3: Modelica model of the heater

Energy balance:

$$
\frac{d}{d t}\left(M_{B 1} \cdot h_{B 1}\right)=\dot{m}_{s w} \cdot h_{s w}-\dot{m}_{B 1} \cdot h_{B 1}-\dot{m}_{d 1} \cdot h_{v 1}
$$

\subsection{The preheaters}

The vapour produced in the heater flows to the preheater-1 located besides, where it condenses as the temperature of the seawater that flows inside the preheater tubes increases. This process is repeated in the successive effects and preheaters. Figure 4 shows the model of the preheater.

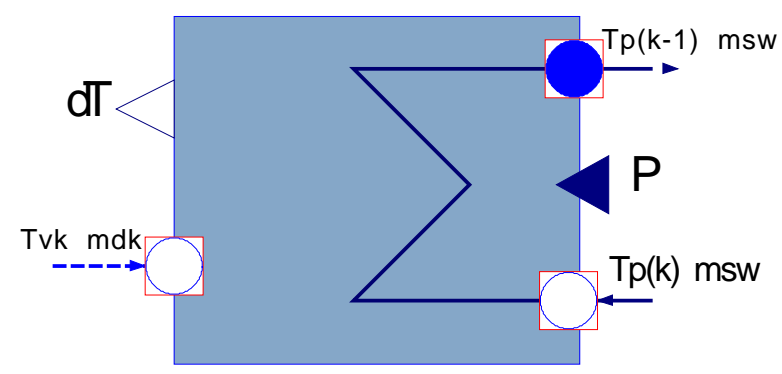

Figure 4: Modelica model of the preheater

The heat transfer rate for each $k$-preheater was calculated using the measured seawater mass flow rate, $\dot{m}_{s w}$, and the temperature difference between the outlet and the inlet:

$$
Q_{p k}=\dot{m}_{s w} \cdot C_{p}\left(T_{p(k-1)}-T_{p k}\right)
$$

Using the overall heat transfer coefficient:

$$
Q_{p k}=U_{p k} \cdot A_{p} \cdot \frac{\left(T_{p(k-1)}-T_{v k}\right)-\left(T_{p k}-T_{v k}\right)}{\ln \frac{T_{p(k-1)}-T_{v k}}{T_{p k}-T_{v k}}}
$$

\subsection{The effects}

The vapour that has not been condensed in the preheater flows to the following effect, where the seawater with a higher brine concentration flows by gravity from the previous effect. Then, the vapour condenses and transfers its latent heat to the seawater producing a new evaporation. Fig.5 shows the model of one effect.

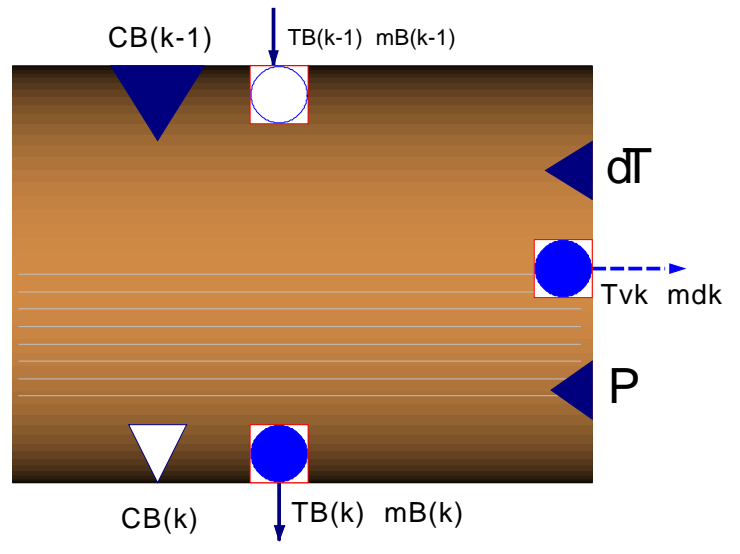

Figure 5: Modelica model of the effect

The heat transfer rate equation for each $k$-effect evaporator is:

$$
Q_{e k}=U_{e k} \cdot A_{e} \cdot\left(d T_{k}+B P E\right)
$$

where $d T$ is the temperature difference between successive effects, which is calculated in the prehetear component.

The distillate mass flow rate in the $k$-effect is:

$$
\dot{m}_{d k}=\frac{Q_{e k}}{\lambda}
$$

The model of each cell or effect is based on mass and energy balances taking into account the distillate produced and the brine mass flow rate from the previous cell:

$$
\frac{d}{d t}\left(M_{B k}\right)=\dot{m}_{B(k-1)}-\dot{m}_{B k}-\dot{m}_{d k}
$$

$$
\frac{d}{d t}\left(M_{B k} \cdot C_{B k}\right)=\dot{m}_{B(k-1)} \cdot C_{B(k-1)}-\dot{m}_{B k} \cdot C_{B k}
$$

$$
\frac{d}{d t}\left(M_{B k} \cdot h_{B k}\right)=\dot{m}_{B(k-1)} \cdot h_{B(k-1)}-\dot{m}_{B k} \cdot h_{B k}-\dot{m}_{d k} \cdot h_{v k}
$$




\section{Simulation results}

The developed model can be used to improve the operation of the plant, studying the effect of the variation in the operating conditions on the MED unit performance and production rate.

The final distillate production will be the sum of the amounts of vapour produced in each effect as follows:

$$
\dot{m}_{d}=\dot{m}_{d h}+\sum_{k=2}^{k=14} \dot{m}_{d k}
$$

Figure 6 shows the results obtained simulating the developed model and using the following inputs:

- MED heating water mass flow rate, $\dot{m}_{M}$, is 12 $\mathrm{kg} / \mathrm{s}$,

- MED inlet heating water temperature, $T_{i M}$, varies between 338 and $345 \mathrm{~K}$ (as shown in Fig. 6)

- seawater mass flow rate inside preheaters 1-13, $\dot{m}_{s w}$, is $1.94 \mathrm{~kg} / \mathrm{s}$,

- preheater-13 inlet seawater temperature, $T_{p 14}$ is about $303 \mathrm{~K}$ (see Fig .6).

As it can be observed in Fig.6, the MED outlet heating water temperature, $T_{O M}$, is about $3.3 \mathrm{~K}$ less than $T_{i M}$. Nevertheless, if the inlet temperature increases, this difference also increases slightly. As it was expected, higher temperatures cause higher thermal consumption. On the other hand, the higher the inlet temperature, the more distillate is produced.

Therefore, the model may be an efficient tool to estimate the thermal consumption depending on the detillate demand. This means that we can predict if the solar resource is enough to reach the production goals or if we should combine it with the use of the heat pump.

\section{Conclusions}

In this paper, a multi-effect distillation unit has been modeled. Physical equations for each one of the main components (the heater, the effect and the preheater) have been developed using the object-oriented Modelica language. The whole plant has been defined with multiple instances of the effect and preheater subsystems properly interconnected between them. First simulation results are promising and the model may be used to improve the operation in the real plant. The main purpose of the model is the prediction of the thermal dynamics of the heater as well as the prediction of the distillate production rate.

\section{Acknowledgements}

The authors would like to thank the CIEMAT Research Centre and the Spanish Ministry of Economy and Competitiveness for funding Project DPI2010-21589C05-02.

\section{References}

[1] D. Alarcón-Padilla, L. García-Rodríguez, and J. Blanco-Gálvez. Assesment of an absorption heat pump coupled to a multi-effect distillation unit within aquasol project. Desalination, 212:303-310, 2007.

[2] M.T. Ali, H.E.S. Fath, and P.R. Armstrong. A comprehensive techno-economical review of indirect solar desalination. Renewable and Sustainable Energy Reviews, 15(8):4187-4199, 2011.

[3] N.H. Aly and A.K. El-Figi. Thermal performance of seawater desalination systems. Desalination, 158(1-3):127-142, 2003.

[4] N.H. Aly and MA Marwan. Dynamic response of multi-effect evaporators. Desalination, 114(2):189-196, 1997.

[5] H. El-Dessouky, I. Alatiqi, S. Bingulac, and H. Ettouney. Steady-state analysis of the multiple effect evaporation desalination process. Chemical engineering \& technology, 21(5):437, 1998.

[6] A.M. El-Nashar. Predicting part load performance of small med evaporators-a simple simulation program and its experimental verification. Desalination, 130(3):217-234, 2000.

[7] M.A. Eltawil, Z. Zhengming, and L. Yuan. A review of renewable energy technologies integrated with desalination systems. Renewable and Sustainable Energy Reviews, 13(9):2245-2262, 2009.

[8] A. Husain. Integrated Power and Desalination Plants. EOLSS Publishers Ltd., 2003.

[9] MH Khademi, MR Rahimpour, and A. Jahanmiri. Simulation and optimization of a six-effect evaporator in a desalination process. Chemical Engineering and Processing: Process Intensification, 48(1):339-347, 2009. 

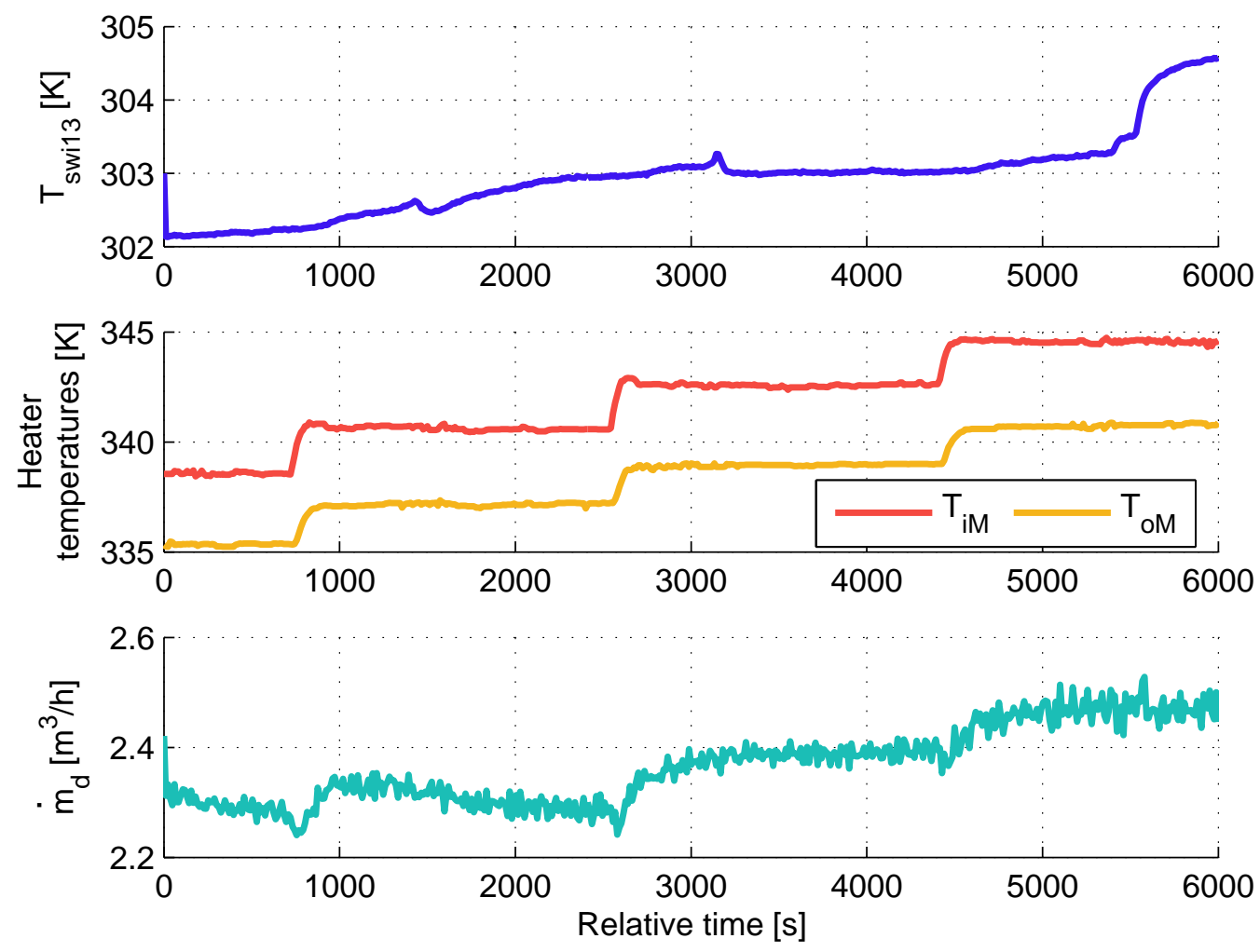

Figure 6: Simulation results of the MED unit model

[10] E. Mathioulakis, V. Belessiotis, and E. Delyannis. Desalination by using alternative energy: Review and state-of-the-art. Desalination, 203:346-365, 2006.

[11] B. Milow and E. Zarza. Advanced med solar desalination plants. configurations, costs, futureseven years of experience at the plataforma solar de almeria (spain). Desalination, 108(1-3):5158, 1997.

[12] P. Palenzuela, D. Alarcon, J. Blanco, E. Guillen, M. Ibarra, and G. Zaragoza. Modeling of the heat transfer of a solar multi-effect distillation plant at the plataforma solar de almeria. Desalination and water treatment, 31(1-3):257-268, 2011.

[13] İ.H. Yılmaz and M.S. Söylemez. Design and computer simulation on multi-effect evaporation seawater desalination system using hybrid renewable energy sources in turkey. Desalination, 2012. 